\title{
SOME STUDIES ON THE TRICHLOROACETIC ACID- PRECIPITATED PROTEINS OF SEMINAL PLASMA IN THE BULL, BUFFALO AND GOAT
}

\author{
K. A. ABRAHAM AND P. M. BHARGAVA \\ Regional Research Laboratory, Hyderabad-9, India
}

(Received 15th November 1962)

\begin{abstract}
Summary. Precipitation of bull, buffalo and goat seminal plasma with trichloroacetic acid did not render the seminal plasma proteins insoluble. On the basis of solubility and dialysibility, the acid-precipitated seminal plasma proteins from bull and buffalo were resolved into three fractions which were quantitatively estimated. Some of the properties of the largest of these fractions from bull, were studied. There was a slight change in the relative proportion of these fractions on storage of semen at room temperature.
\end{abstract}

\section{INTRODUCTION}

During the course of earlier work (Bhargava, Bishop \& Work, 1959) on protein synthesis in mammalian semen, a part of the trichloroacetic acid-precipitated seminal plasma protein was observed to be soluble in water and/or dilute salt solution, suggesting that it may not have been denatured. Precipitation of blood plasma albumin with trichloroacetic acid (TCA) has been shown to have no effect on its physical, chemical and biological properties (Schwert, 1957). These observations prompted a further investigation of the TCA-precipitated seminal plasma proteins; preliminary findings are reported here.

\section{METHODS}

Seminal plasma was separated by centrifugation from a known amount of suitably diluted bull, buffalo or goat semen, stored in the cold for less than $3 \mathrm{hr}$ after collection. The diluted seminal plasma was treated with an equal volume of $10 \% \mathrm{TCA}$ at room temperature for $5 \mathrm{~min}$. The TCA precipitate was washed twice each with $5 \% \mathrm{TCA}$ and $5 \%$ sodium chloride solution $(\mathrm{NaCl})$ and then extracted exhaustively with water; the $\mathrm{NaCl}$ washes contained less than $2 \%$ of the protein in the TCA precipitate. Almost all the precipitate (which had 13 to $14 \%$ nitrogen, and a typical protein spectrum in the ultraviolet) dissolved in water; the insoluble residue accounted for less than $3 \%$ of the dry weight of seminal plasma for all the animals studied, and did not contain any protein or lipids, which provides further evidence (Mann, 1954) in favour of the 


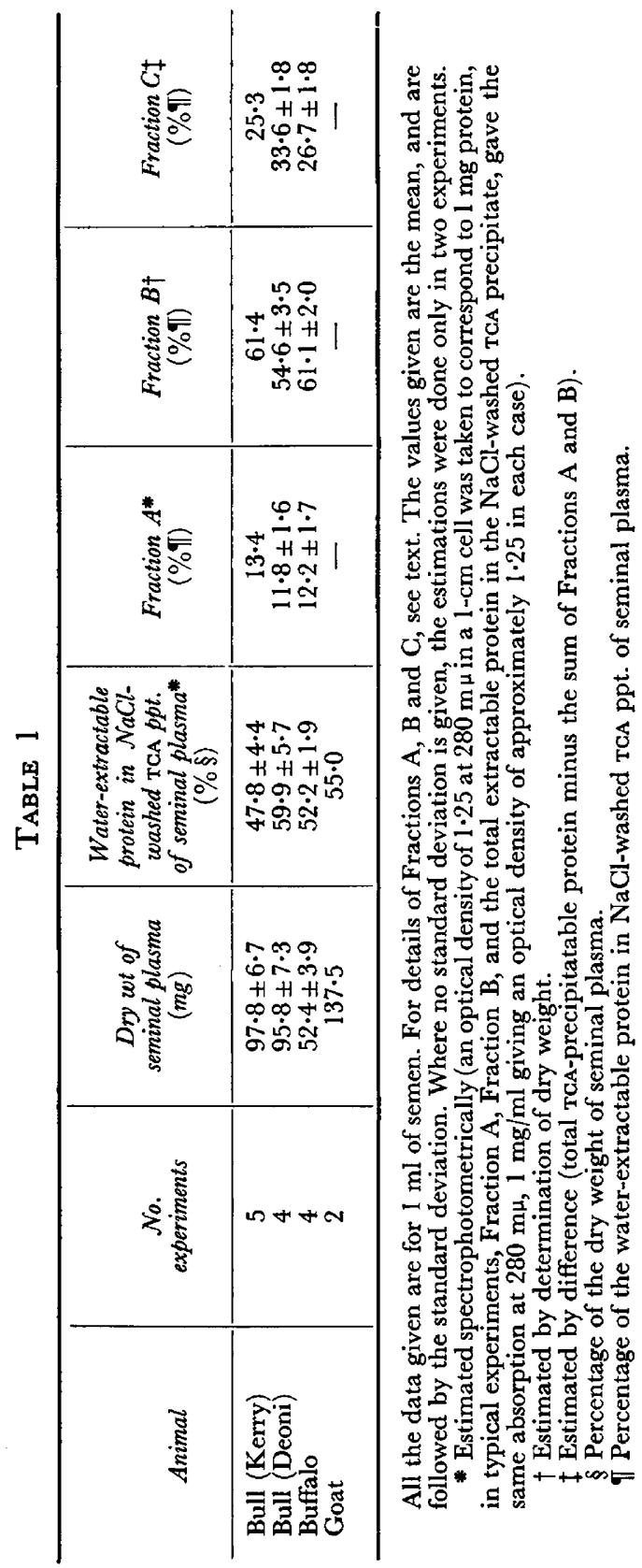


absence of free, acid-insoluble lipids (or lipoprotein) in mammalian seminal plasma. The dry weight of seminal plasma and the protein content of the aqueous extract of the TCA precipitate of seminal plasma, are given in Table 1 for a series of experiments on a Kerry bull, a Deoni bull, a Murrah buffalo and a Jamnapari goat. The TCA-precipitated sperm proteins were completely insoluble in water and/or dilute salt solutions.

\section{RESULTS}

Dialysis against water for $72 \mathrm{hr}$ of the aqueous solution (obtained as above) of the washed TCA-precipitated seminal plasma proteins yielded two non-dialysable fractions, $\mathrm{A}$ and $\mathrm{B}$, and one dialysable fraction, $\mathrm{C}$. Of the former, one (Fraction A) was soluble in both water and dilute salt solutions, while the other (Fraction B) was soluble only in dilute salt solutions; Fraction B was initially extracted in water owing to the presence of salt left over in the TCA precipitate after the $\mathrm{NaCl}$ washing, and was precipitated on dialysis. The relative proportion of Fractions A, B and C from two bulls and a buffalo are given in Table 1. No significant loss of TCA-precipitable nitrogen on dialysis of bull seminal plasma against a phosphate buffer was observed earlier (Larsen \& Salisbury, 1953); the origin of Fraction C, is, therefore, not clear. Storage of buffalo semen for $3 \mathrm{hr}$ at room temperature $\left(30^{\circ} \mathrm{C}\right)$ caused no reduction in the total TCA-precipitatable protein but resulted in a 65 to $80 \%$ decrease in the non-dialysable fraction, A. Most of the protein lost from Fraction A was recovered in the other non-dialysable fraction, $\mathrm{B}$, and there was only a 10 to $15 \%$ increase of protein in Fraction C. Fraction $\mathrm{C}$ is, therefore, unlikely to be derived as a result of proteolysis (Mann, 1954) of Fractions A and/or B during the storage of semen before treatment with TCA.

Following Sanger's fluorodinitrobenzene method, the average molecular weight of the polypeptide chains of Fraction B from the Kerry bull was found to be 2150,2410 and 2560 in three experiments, suggesting that this fraction consists of small polypeptide chains; arginine, glycine, serine and alanine were detected as the N-terminal amino acids of Fraction B, indicating a heterogeneity in its polypeptide chains. Preliminary experiments on the amino acid composition of Fraction B from Kerry bull indicated the presence of a high concentration of the sulphur-containing amino acids (methionine and cysteine, approximately 12 and $6 \mathrm{~g}$, respectively, per $100 \mathrm{~g}$ protein). It is possible that each component of Fraction B consists of several peptide chains joined together by the abundant cysteine residues.

This investigation also indicates that proteins of seminal plasma are qualitatively different from those of blood plasma. The latter (including globulins) are completely soluble in water after precipitation with TCA from whole plasma and the removal of TaA by dialysis (Abraham \& Bhargava, 1963).

Although precipitation with TCA does not render any of the seminal plasma proteins studied insoluble in water and/or dilute salt solutions, it may affect the structure, the biological properties and the other physical properties of the proteins. Further work on the characterization of the TCA-precipitated proteins, and on their relation to the native proteins of mammalian seminal plasma, is in progress. 
We are grateful to the Department of Animal Husbandry, Government of Andhra Pradesh, for the supply of semen and to Dr S. Husain Zaheer for his encouragement; one of us (K. A. A.) is also grateful to the Council of Scientific and Industrial Research, New Delhi, for a Research Fellowship

\section{REFERENCES}

Abraham, K. A. \& Bhargava, P. M. (1963) Effect of acid precipitation on the solubility and the electrophoretic characteristics of plasma proteins. F. sci. industr. Res. (In press).

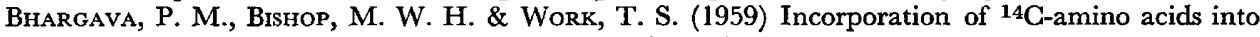
the proteins of bull spermatozoa. Biochem. 7. 73, 247.

Larsen, B. L. \& Salisbury, G. W. (1953) The proteins of bovine seminal plasma. Preliminary and electro-phoretic studies. F. biol. Chem. 206, 741.

MaNn, T. (1954) Biochemistry of semen, pp. 111, 130. Methuen, London.

ScHWERT, G. W. (1957) Recovery of native bovine serum albumin after precipitation with trichloroacetic acid and solution in organic solvents. 7. Amer. chem. Soc. 79, 139. 